\title{
Correction to: Comparison from Simulated Al 0.3 Ga 0.7 As/GaAs/ Ge and Al 0.3 Ga 0.7 As/GaAs/Si/Ge to Experimental InGaP/GaAs/ InGaNAsSb/Ge for Optimized Utilization of the Solar Spectrum
}

\author{
Hongxi Li ${ }^{1} \cdot$ Yulin Tian ${ }^{2} \cdot$ Ling Shen ${ }^{2} \cdot$ Chusheng Liu ${ }^{1}$
}

Published online: 27 October 2021

(C) The Minerals, Metals \& Materials Society 2021

\section{Correction to: Journal of Electronic Materials, Vol. 50, No. 4, 2021 \\ https://doi.org/10.1007/s11664-020-08722-6}

Figures 6(a)(b)(c) and Figure 7(a)(b) did not credit the original source. These figures have been reproduced from Nature Materials (2014) 13, 593-598, with permission.

The additional figures below have been included as Fig. 8(a) and (b).

The original article can be found online at https://doi.org/10.1007/ s11664-020-08722-6.

Ling Shen

shenling1314@cumt.edu.cn

$\triangle$ Chusheng Liu

liuchusheng@cumt.edu.cn

1 School of Mechanical and Electrical Engineering, China University of Mining and Technology, Xuzhou 221116, Jiangsu, People's Republic of China

2 School of Materials and Physics, China University of Mining and Technology, Xuzhou 221116, Jiangsu, People's Republic of China 
(a)

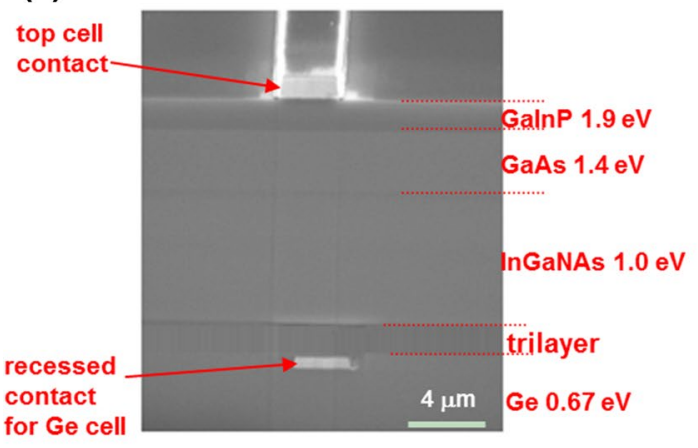

Fig. 8 (a) SEM images (cross-sectional view) of a 3J/trilayer/Ge cell, showing the aligned metal contact lines and the interfacial trilayer. (b) XRD of $\mathrm{TiO}_{2}$ film for Trilayer. (a) Presents SEM images (crosssectional view) of a mechanically stacked $3 \mathrm{~J} /$ trilayer/Ge cell, showing the aligned metal contact lines and the interfacial trilayer. The XRD patterns of $\mathrm{SiO}_{2}$ and $\mathrm{TiO}_{2}$ for trilayer film have been obtained. Since (b)

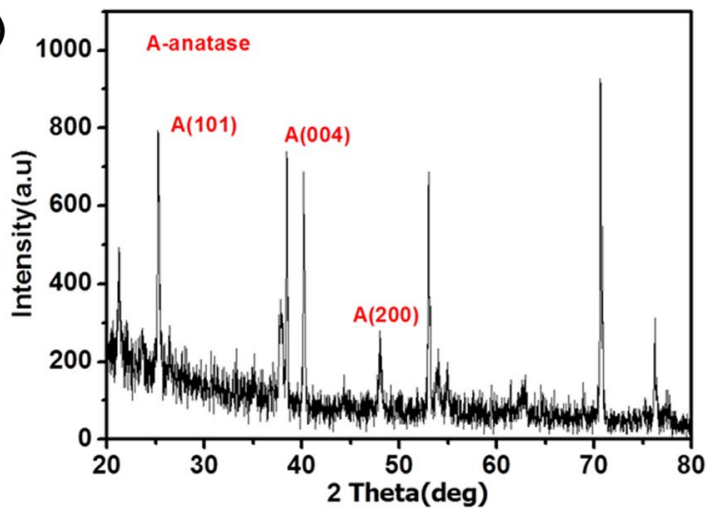

$\mathrm{SiO}_{2}$ is amorphous, only XRD of $\mathrm{TiO}_{2}$ film has been displayed as (b). The three broad characteristic peaks at $2 \theta=25.2^{\circ}, 37.8^{\circ}, 48.1^{\circ}$ of anatase phase have been observed, which were well indexed to (10 1), ( $\left(\begin{array}{lll}0 & 0 & 4\end{array}\right)$ and ( $\left(\begin{array}{lll}2 & 0 & 0\end{array}\right)$ plane diffraction of anatase $\mathrm{TiO}_{2}$. Therefore, it can be considered that $\mathrm{TiO}_{2}$ for $\mathrm{TiO}_{2} / \mathrm{SiO}_{2} / \mathrm{TiO}_{2}$ trilayer film is anatase $\mathrm{TiO}_{2}$.

Publisher's Note Springer Nature remains neutral with regard to jurisdictional claims in published maps and institutional affiliations. 